mittees to have lists of those undergoing higher training; this will facilitate later accreditation as a specialist.

An outline of the arrangements for both of these procedures is given in the Second Report of the JCHMT recently published and referred to previously (29 November, p 532); the report is obtainable (price $£ 1.50$ including postage) at this address. However, in addition we have thought it worth while, through your columns, to inform all senior registrars (or equivalent) in the relevant specialties that they should soon seek enrolment by applying on the prescribed form, obtainable at the same address (see below for details). In the case of haematology application has also to be made to the Royal College of Pathologists, 2 Carlton House Terrace, London SW1Y 5AF. Even if a senior registrar post has not yet been visited and approved the holder should proceed to enrolment. Even if, after one of the current visits, the senior registrar post has not been approved, this does not affect the present holder, who should apply for enrolment.

It is expected that (except in the specialties of community medicine, dermatology, haematology, neurology, paediatrics, and venereology) most senior registrars in adult medicine will also seek enrolment in general (internal) medicine, though this is not mandatory. On application for enrolment they will therefore be sent two forms, one for general (internal) medicine and one for their chosen specialty. In the case of haematology two forms will be sent, one for the JCHMT and one for the Royal College of Pathologists. In the case of paediatric subspecialties it will be expected that enrolment will usually be sought also in general paediatrics; two forms will therefore be sent.

Those who are in the last six months of the training period recommended in the Second Report should, after enrolment, later apply to the JCHMT for the prescribed forms for accreditation. Again, where relevant, two forms will be sent for those who have been enrolled both in general (internal) medicine and in another specialty and for those who have been enrolled both in general paediatrics and in a paediatric subspecialty. Those who have been enrolled in haematology will receive two forms, one of which should be submitted to the Royal College of Pathologists.

For the present no consultant already in a post before 1 January 1977 need seek accreditation unless, in the future, he requires this in applying for a post in another country of the European Economic Community. After January 1977 any trainee who is appointed to a consultant post before he has achieved accreditation, which is entirely possible (see p 12 of the report), should apply to the JCHMT for accreditation, which would normally be granted.

The question of some sort of specialist registration after a duration of training less than that recommended in the Second Report but conforming to the minimal standards laid down by the Commission of the European Economic Community is still under discussion and no action is contemplated at present.

It will be appreciated that the publication of the Second Report, and this letter, may result in a very large mass of correspondence for the hard-pressed staff of the JCHMT, which is still receiving quite inadequate governmental financial support. We hope that trainees will bear with us if there are delays in correspondence. To simplify administration we suggest that those applying for enrolment should do so in the following months :
Names beginning with

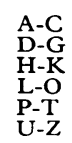

Similarly we suggest that those seeking accreditation, who will mainly be those in the last six months of their training, should spread their applications as follows:
Names beginning with
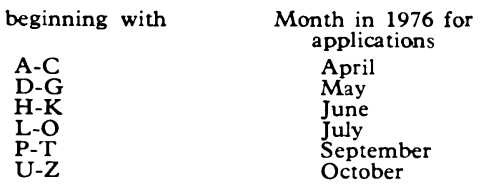

Everyone will appreciate that this is a major administrative exercise which may take some time to be accomplished. We will do our best to deal with difficulties but appeal in advance for tolerance.

JOHN CROFTON
Chairman,

Royal College of Physicians,

11 St Andrew's Place,

Regent's Park,

\section{Vesicoureteral reflux and its familial} distribution

SIR,-Your leading article (27 December, p 726) admirably draws attention to a group of patients in whom vesicoureteral reflux (VUR) appears to be familial. It is important to differentiate clearly between the possibly inherited problem of VUR and the resulting renal damage (chronic pyelonephritis, reflux nephropathy). In order to document the familial problem fully it will be necessary to determine the hereditary pattern of VUR and the incidence of renal scarring within this group and compare them with a similar control population-an almost impossible task to perform with any degree of accuracy.

You suggest that as full radiological screening of all members of a family is impracticable and unjustified a compromise may be the zealous testing of the urine in siblings who are unwell for any reason and urography and/or cystography in families with more than one affected member or in whom renal scarring is evident. This is unsatisfactory, for, although the results would be of interest, they would probably not be of benefit to the patient. The discovery of VUR in an infant after its first infection may be too late, as scar formation in susceptible areas of the kidneys may already have been initiated. ${ }^{\text {It }}$ is well known that most children with chronic pyelonephritis have demonstrable scars when first seen, and the development of further areas of scarring while under medical supervision is very rare.

A different compromise of greater potential benefit would be to concentrate on families in which the affected child is the eldest (but still under, say, 5 years) and preferably the only child. All subsequent siblings could then be investigated by cystography shortly after birth and those with VUR identified at a very early stage. At present there is no method of selecting from this group of infant refluxers all those in whom pyelonephritic scarring is likely to develop, but the presence of gross reflux appears to carry the greatest risk. ${ }^{3}$ These children could be treated prophylactically by reimplantation of the ureters or continuous chemotherapy. The demonstration of a reduction in the incidence of renal scarring in children so treated would be of the greatest benefit and help to de- termine the policy for the remainder of the population of refluxing children.

The results of surgery in this age group are not known at present and perhaps chemotherapy should remain the initial treatment of choice until the results of a trial of surgery versus conservative treatment for infants with VUR become available. Such a trial is at present in progress jointly between the Institute of Urology and the Hospital for Sick Children, Great Ormond Street, London.

Institute of Urology,

P G RANSLEY

London WC2

1 Lancet, 1974, 2, 1120.
2 Smellie, J M, British fournal of Hospital
Medicine, 1974, 12, 485. F T, and Utley, W L,
3olleston, G L, Shannon, F T, 1, 460.
British Medical fournal, 1970,

Carrier solutions for low-level intravenous insulin infusion

SIR,-Recently there has been growing interest in the use of low-dose continuous infusions of insulin in the management of diabetic crisis. A major advantage of this technique is that the patient's response is predictable in a way that was previously not possible. This was to be anticipated, since, in contrast to previous techniques, the infusion of insulin produces a sustained steady-state concentration of insulin in the plasma, the magnitude of which is directly proportional to the infusion rate. ${ }^{1}$ Because of the very short half life of the hormone, plasma insulin concentration can be changed more or less instantaneously by simply altering the rate of infusion.

The technique was popularised following our studies on insulin metabolism. ${ }^{12}$ In these and all other studies which involved the use of polypeptide hormones we have been careful to use albumin as a carrier protein since insulin and other polypeptide hormones are particularly prone to non-specific adsorption to "active surfaces." It seemed only logical therefore to add carrier protein to insulin infusions used therapeutically. Albumin is not easily available in convenient amounts and for this reason some have infused insulin without added carrier protein and, because they have so far encountered no problems, have encouraged others to adopt this practice.

The article by Dr E W Kragen and his colleagues (23 August, p 464) and the subsequent letter from Dr P F Semple and others (25 October, p 228) again highlight the fact that insulin losses from simple salt solutions are substantial and unpredictable ${ }^{3}$ and advocate the use of carrier proteins-a

The use of low-dose insulin infusions in the management of diabetic coma has been included in the most recent edition of an already well-established textbook on the management of diabetes, with the statement that "insulin, in the concentration we use, does not adhere to the plastic of syringe or tubing so it is not necessary, as had been thought, to add human albumin to prevent adsorption."4 This seems potentially dangerous since all adequately controlled studies that I am aware of are in agreement with the results obtained by Dr Semple and his colleagues, indicating that insulin losses are significant even at concentrations four times view that I wish to endorse. for real urgency, may be dealt with outside this timetable.

onth in 1976 for
applications
February
March
April
May
June
July


higher than those recommended by Oakley et al.

How then should we proceed? I would like to propose that carrier protein be always added to low-dose continuous infusions of insulin. This can be in the form of human albumin or plasma protein at the concentration of not less than $2 \mathrm{~g} / \mathrm{l}$. When suitable preparations are not immediately available use can be made of the patient's own plasma proteins. A simple effective way of preparing a suitable solution is to take $5 \mathrm{ml}$ of the patient's blood into a $50-\mathrm{ml}$ syringe, make up the desired volume with physiological saline, and then add the required amount of insulin and mix well. When the syringe is placed in the syringe-pump the red cells sediment at the bottom and the resulting solution has approximately $4 \mathrm{mg} / \mathrm{ml}$ carrier protein which will be in stable solution for as long as 24 hours if necessary. It seems to me that this technique is so simple and safe that it can always be used when convenient preparations of carrier proteins are not at hand.

\section{PETER SÖNKSEN}

Department of Medicine

St Thomas's Hospital Medical School,

London SEI

1 Sönksen, $\mathrm{P} H$, et al, Clinical Science and Molecular Medicine, 1973, 45, 633.

Sönksen, P H, et al, Lancet, 1972, 2, 155.

Sönksen, P H, et al, Diabetologia, 1965, 1, 208.

Oakley, W G, Pyke, D A, and Taylor, K W,
Diabetes and its Management, 2nd edn, p 112.
Oxford, Blackwell Scientific, 1975.

SIR,-Dr E W Kraegen and others (23 August, p 464) state that when dilute solutions of insulin are prepared for intravenous infusion significant losses of the order of $60-80 \%$ will occur as a result of adsorption of insulin to glass or plastic surfaces.

In order to check this statement we made up insulin solutions in physiological saline containing $40 \mathrm{U} / 1$ and left these in contact with both clean glass and polyethylene surfaces for two hours with intermittent shaking. Immediately afterwards the solutions were assayed against the 4th International Insulin Standard using the official method of the British Pharmacopoeianamely, mouse convulsion assay. We have not been able to detect a significant loss of insulin from any of these solutions.

The low recoveries reported by $\mathrm{Dr}$ Kraegen and his colleagues may have been due to their use of a radioimmunoassay technique for assaying insulin in solutions that had been frozen at $-20^{\circ} \mathrm{C}$ and then subsequently thawed. It has been our experience that this always leads to low recoveries of insulin, probably as a result of disruption of the insulin-antibody binding sites.

Research Biological Support,

M BURTON

Company Ltd,

Nottingham

\section{6}

\section{Laboratory diagnosis of malaria}

SIR,-Diagnosis of malaria is made in the laboratory by the use of stained thick and thin blood films, which should be made immediately the patient is bled. Microscopical examination of blood films made from blood previously collected into anticoagulants can produce difficulties in identification of malaria parasites.

We performed a simple experiment by taking blood from two patients (one with Plasmodium vivax malaria, one with $P$ malariae infection). Immediate thin films were made and the rest of the blood was put into containers with either heparin, sodium oxalate, or EDTA as anticoagulant. The containers were left on the bench at room temperature and thin films made at varying intervals up to 48 hours later. The slides were stained together and examined blind by one of us (PGS). Within 30 minutes of being in heparin or sodium oxalate distortion of parasites had occurred; this worsened with the passage of time, rendering species diagnosis, and occasionally even a diagnosis of malaria, difficult if not impossible. Some distortion occurred with EDTA but was not so marked as with heparin or sodium oxalate, especially within about four hours of bleeding

As a rule malaria should be diagnosed on blood films made at the patient's bedside. If this is not possible blood should be drawn by venepuncture, placed in an EDTA container, and films made preferably within the hour and certainly not more than three hour later.

Hospital for Tropical Diseases,

G H REE

London NW1

P G SARGEAUN

\section{Dependence on antiparkinsonian drugs}

SIR,-I wish to add to $\operatorname{Dr} M$ E Shariatmadari's case report of orphenadrine dependence (23 August, p 486). A drug monitoring programme begun in 1973 at our Modecate (fluphenazine) clinic revealed similar problems of drug dependency with benzhexol (trihexyphenidyl hydrochloride) This was apparent in our younger schizophrenics who were on the fringe of the drug scene. The effects described included elation or "highs" and the drug was used for "tripping on," relieving depression swapping for other illicit drugs, or mixing with alcohol or Mandrax. We observed several patients after taking excessive amounts present with an acute brain syndrome. Frequently this group demanded more tablets from the clinic, the pharmacy, the duty doctor, or other hospitals. Their resistance to reduction or cessation of antiparkinsonian drugs $s^{1}$ played a part in the high proportion of our patients $(57.5 \%)$ receiving these drugs in 1973. Feeding back to the hospital staff of this problem and a greate use of benztropine has reduced our antiparkinsonian medication to $30.3 \%$ in a large sample of 379 outpatients.

Both orphenadrine and benzhexol have hepatic enzyme-inducing properties. Othe non-therapeutic drug interactions include a potentiating and worsening of tardive dyskinesia. ${ }^{2}$ With over 400000 patients on depot neuroleptics world wide, the clinician should avoid adding to the problems of the schizophrenic.

Royal Park Psychiatric Hospital,

PETER MARRIOT

Parkville,

Victoria, Australia

1 Marriott, P, Grigor, J, and Hiep, A, British Fournal of Psychiatry, 1975, 126, 204 .
Marriott, P, Medical fournal of Australia, 1975,
2, 33.

\section{How much can ancillaries take over?}

SIR,-May I comment on the statement, "Of course, throughout much of Europe and the USA nurses give most of the anaesthetics. So why have a specialty of anaesthesia at all?" which is attributed to your good self as chairman of the conference on medical manpower held at Canterbury last November (3 January, p 29)? I hope that this was merely a provocatively inaccurate remark from the chair calculated to stimulate discussion. I cannot believe that anyone in your position could possibly fail to distinguish between the skill of administering anaesthesia and the responsibilities of the modern specialty of anaesthesia.

It is true that nurses do administer anaesthesia in other countries, but they are increasingly, and in some countries exclusively, under the guidance of physician anaesthetists. The medical members of the modern specialty of anaesthesia organise and carry out many more tasks within the hospital service besides their original raison d'être of administering anaesthesia, including emergency aid and resuscitation, preand postoperative care, intensive therapy, and pain control.

It must be obvious that the principle of having "six nurse-anaesthetists supervised by one consultant anaesthetist," as $\mathrm{Mr}$ F S A Doran suggests in the same report, would be impracticable in most hospitals in the United Kingdom because of the peculiar British architectural custom of distributing individual operating theatres in isolated sites all over the hospital complex. Whatever future attitudes to the possible use of the nurse-anaesthetist in the UK may be, however, I trust that you will acknowledge that she would in no way be a substitute for the modern physician-anaesthetist with his many executive responsibilities within the hospital

T B Boulton Editor, Anaesthesia

Association of Anaesthetists of Great Britain and Ireland,

London WC1

${ }_{*}^{*}$ Dr Boulton can rest assured that the remark to which he refers was indeed made in a light-hearted spirit with the sole purpose of stimulating discussion.-ED, BMF.

\section{SLE precipitated by antibiotics in Sjögren's syndrome}

SIR,-The claim by Dr D M Grennan and his colleagues (15 November, p 385) of "multi-system features of systemic lupus erythematosus (SLE)" developing on two separate occasions in a patient with Sjögren's syndrome after antibiotics and their conclusions on the relationship of Sjögren's syndrome to SLE do not meet current diagnostic criteria.

On the first admission SLE was diagnosed from LE cells in the patient's blood film, worsening poly arthritis, pericarditis, and a "borderline abnormal" DNA binding of $28 \%$. However, LE cells may be found in uncomplicated rheumatoid arthritis and more commonly in Siögren's syndrome. ${ }^{1}$ and after anti-inflammatory drugs. ${ }^{2}$ Pericarditis can be complication of rheumatoid arthritis $(10 \%$ of inpatients with rheumatoid disease ${ }^{3}$ ). DNA binding values of over $30 \%$ have been recorded in some cases of Sjögren's syndrome unassociated with SLE $;^{4}$ thus on this occasion the patient had only 